\title{
Analysis of Two-Commodity Continuous Review Inventory System in Supply Chain
}

\author{
S.Priscilla Jane ${ }^{\alpha}$, R. Bakthavachalam ${ }^{\beta,}$ A. Nagarajan*, C.Elango ${ }^{\#}$ \\ ${ }^{\alpha}$ Department of Mathematics, Bethlahem Institute of Engineering ,Karungal. \\ ${ }^{\beta}$ Department of Mathematics, Fatima Michael College of Engineering \& Technology, Madurai. \\ * PG and Research Department of Mathematics, VO C College, Thoothukudi. \\ \#PG and Research Department of Mathematics, C P A College, Bodinayakanur.
}

\begin{abstract}
This paper considers a two commodity continuous review inventory system. Continuous review inventory control of a single item at a single location had been considered by many researchers in past. We extend this inventory control strategy to two-echelon system, which is a building block for serial supply chain. The inventory control system consists of two warehouse $\left(W H_{i}\right)$, Two Distribution Centre's $\left(D C_{i}\right)$ each associated with a retailer and handling two non-identical products. A $(s, S)$ type inventory system with Poisson demand and exponentially distributed lead times is assumed at retailer node. The items are supplied to the retailers in packs of $Q_{i}\left(=S_{i}-s_{i}\right)$ items from the distribution center $\left(D C_{i}\right)$ which has instantaneous replenishment facility from an abundant source (manufacturer). The steady state probability distribution and the operating characteristics are obtained explicitly. The measures of system performance in the steady state are obtained. The results are illustrated with numerical examples.
\end{abstract}

Keywords: Supply Chain, Inventory control, Multi-echelon system, two commodity continuous review inventory, Optimization.

\section{Introduction}

Keeping an inventory (stock of goods) for future sale or use is common in business. In order to meet demand on time, companies must keep on hand a stock of goods that is awaiting sale. The purpose of inventory theory is to determine rules that management can use to minimize the costs associated with maintaining inventory and meeting customer demand. Inventory is studied in order to help companies save large amounts of money. Inventory models answer the questions: (1) when should an order be placed for a product? (2) How large should each order be? The answer to these questions is collectively called an inventory policy. Companies save money by formulating mathematical models describing the inventory system and then proceeding to derive an optimal inventory policy. In the face of uncertainty it is more complicated to determine the inventory control policy and the most frequent uncertain factor is the stochastic nature of customer demand.

A Supply chain may be defined as an integrated process wherein a number of various business entities (i.e., suppliers, manufacturers, distributors, and retailers) work together in an effort to: (1) acquire raw materials, (2) convert these raw materials into specified final products, and (3) deliver these final products to retailers. The process and delivery of goods through this network needs efficient communication and transportation system. The supply chain is traditionally characterized by a forward flow of materials and products and backward flow of information.

A successful supply chain responds to customer's requirements with minimum cost. In general, organizations which are members of a supply chain are independent of each other and try to maximize their own benefits. Appropriate behavior of each member is necessary but does not suffice to have a competitive supply chain. A supply chain coordination mechanism leads members to behave such that the entire supply chain satisfies customer demand with minimum costs. The goal is to minimize operational costs of the whole supply chain while satisfying customer demand.

Inventory decision is an important component of the supply chain management, because Inventories exist at each and every stage of the supply chain as raw material or semi-finished or finished goods. They can also be as Work-in-process between the stages or stations. Since holding of inventories can cost anywhere between $20 \%$ to $40 \%$ of their value, their efficient management is critical in Supply Chain operations

Stochastic inventory model have received considerable attention in inventory literature. Inventory systems of (s, S) type for single commodity have been studied quite extensively in the past. The first quantitative analysis in inventory studies started with the work of Harris (1915) [9].Clark and Scarf (1960) [6] had put forward the multi-echelon inventory first. They analyzed a N-echelon pipelining system without considering a lot size, Recent developments in two-echelon models may be found in Q.M. He and E.M. Jewkes (1998)[10].Sven Axsäter (1990)[3] proposed an approximate model of inventory structure in SC. One of the oldest papers in the field of continuous review multi-echelon inventory system is a basic and seminal paper 
written by Sherbrooke [15] in 1968. A Complete review was provided by Benita M. Beamon (1998)[4]. the supply chain concept grow largely out of two-stage multi-echelon inventory models, and it is important to note that considerable research in this area is based on the classic work of Clark and Scarf (1960)[6]. A continuous review perishable inventory system at Service Facilities was studied by Elango (2001) [7]. A continuous review $(\mathrm{s}, \mathrm{S})$ policy with positive lead times in two-echelon Supply Chain in single item was considered by Krishnan. K and Elango.C. 2005 [12].

The modelling of multi-item inventory system under joint replenishment has been receiving considerable attention for the past three decades. In continuous review inventory systems, Ballintfy [1964] and Silver [1974] have considered a coordinated reordering policy. Sivazlian [1971] considers the stationary characteristics of a multi-commodity inventory problem. Krishnamoorthy, Lakshmi and Basha [1994][13] have dealt with a two commodity inventory problem. Kalpakam and Arivarigan [11] analyzed a multi-item inventory model with renewal demands under a joint replenishment policy. Anbazhagan and Arivarignan [1] have analyzed two commodity inventory systems under various ordering policies. Yadavalli et. al., [16] have analyzed a model with joint ordering policy and varying order quantities.

The paper is organized as follows. In section two, a mathematical model for the problem is presented along with some important notations used in the paper. Both transient and steady state analysis are done in section three. In section four, the operating characteristics of the system are shown. In section five, deals with the cost analysis for the operation. In section six, some numerical examples are given section. Finally, section seven concludes the paper.

\section{Mathematical Model}

The inventory control system in supply chain considered in this paper is defined as follows.

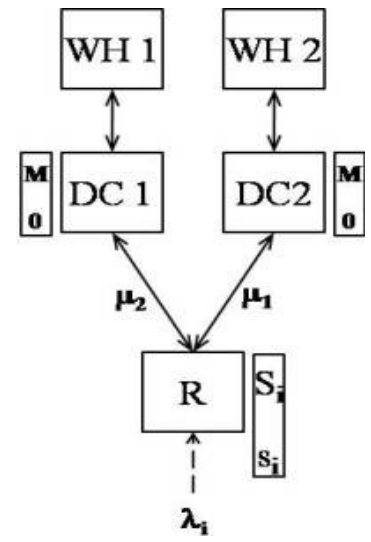

Figure 1: Two-commodity Inventory System in Supply Chain

We consider a serial supply chain consisting of a two warehousing facility (WH), two distribution centre (DC) and single retailer (R) dealing with two non identical products.

We assume that finished products are supplied from WHi to DCi which adopts $(0, \mathrm{M})$ replenishment policy then the product is supplied to $\mathrm{R}$ who adopts $\left(\mathrm{s}_{\mathrm{i}}, \mathrm{Q}_{\mathrm{i}}\right)$ policy. The demands at retailer node follows independent Poisson distribution with rate $\lambda_{\mathrm{i}}(\mathrm{i}=1,2)$. Supply to the Manufacturer in packets of $\mathrm{Q}$ items is administrated with exponential lead time having parameter $\mu_{\mathrm{i}}(>0)$. The replenishment of items in terms of pockets is made from WH to DC is instantaneous. Demands that occur during the stock out periods are assumed to be lost sales. In this model the maximum inventory level at $\mathrm{R}$ node $\mathrm{S}_{\mathrm{i}}$ is fixed and the reorder level $\mathrm{s}_{\mathrm{i}}$ is varying such that $\mathrm{S}_{\mathrm{i}}-\mathrm{S}_{\mathrm{i}}(\mathrm{i}=1,2)$ and $\mathrm{Q}_{\mathrm{i}}>\mathrm{s}_{\mathrm{i}}$. The maximum inventory level at $\mathrm{DC}_{\mathrm{i}}$ is $\mathrm{M}_{\mathrm{i}}\left(\mathrm{M}_{\mathrm{i}}=n \mathrm{Q}_{\mathrm{i}}\right)$. In this twocommodity inventory system we assumed that two reorder levels and to place order for each commodity independent of other. Here joint order is not possible because two different product from different MF through different DC.

The optimization criterion is to minimize the total cost rate incurred at all the location subject to the performance level constraints. According to the assumptions the on hand inventory levels at all the nodes follows a random process.

\section{Notations :}

$[R]_{\mathrm{ij}} \quad:$ The element /sub matrix at $(\mathrm{i}, \mathrm{j})^{\text {th }}$ position of $\mathrm{R}$.

0 : Zero matrix.

I : Identity matrix.

e : A column vector of ones of appropriate dimension. 
$\mathrm{k}_{\mathrm{Di}} \quad$ : Fixed ordering cost, regardless of order size at $\mathrm{DC}_{\mathrm{i}}$ nodes $(\mathrm{i}=1,2)$.

$\mathrm{k}_{\mathrm{R}} \quad$ : The average ordering cost at retailer node.

$\mathrm{k}_{\mathrm{W}} \quad:$ the average setup cost for at warehouse

$\mathrm{h}_{\mathrm{Di}} \quad$ : The holding cost per unit of item per unit time at $\mathrm{DC}_{\mathrm{i}}$ nodes $(\mathrm{i}=1,2)$.

$h_{R} \quad$ : The average holding cost per unit of item per unit time at retailer nodes.

$\mathrm{h}_{\mathrm{w}} \quad$ : The average holding cost per unit of item per unit time at warehouse

g : :The unit shortage cost at retailer nodes.

$\sum_{i=1}^{k} a_{i}=a_{1}+a_{2}+\ldots+a_{k} \cdot \quad \sum_{i=0}^{n Q} * i=0+Q+2 Q+\ldots+n Q$.

\section{Analysis}

Let $I_{i}(t),(i=1,2,3,4)$ denote the on-hand inventory levels for commodity-1, commodity-2 at retailer node and DC1, DC2 respectively at time $\mathrm{t}+$. From the assumptions on the input and output processes,

$\mathrm{I}(\mathrm{t})=\left\{\left(\mathrm{I}_{\mathrm{i}}(\mathrm{t}),: \mathrm{t} \geq 0\right\},(\mathrm{i}=1,2,3,4)\right.$ is a Markov process with state space

$$
E=\left\{\begin{array}{l}
(i, k, m, o) / i=S,(S-1), \ldots, s_{1},\left(s_{1}-1\right), \ldots, 2,1,0 ., \mathrm{k}=S_{2},\left(S_{2}-1\right), \ldots, s_{2},\left(s_{2}-1\right), \ldots, 2,1,0 . \\
\mathrm{m}=\mathrm{n}_{1} \mathrm{Q}_{1},(\mathrm{n}-1) \mathrm{Q}, \ldots, \mathrm{Q}_{1} \text { and } \mathrm{o}=\mathrm{n}_{2} \mathrm{Q}_{2},\left(\mathrm{n}_{2}-1\right) \mathrm{Q}_{2}, \ldots, \mathrm{Q}_{2} .
\end{array}\right\}
$$

Since $\mathrm{E}$ is finite and all its states are recurrent non-null, $\{\mathrm{I}(\mathrm{t}), \mathrm{t} \geq 0\}$ is an irreducible Markov process with state space $\mathrm{E}$ and it is an ergodic process. Hence the limiting distribution exists and is independent of the initial state.

The infinitesimal generator of this process $R=(a(i, k, m, o: j, 1, n, p))_{(i, k, m, o)},(j, 1, n, p) \in E$ can be obtained from the following arguments.

- The arrival of a demand for commodity-1 at retailer node makes a state transition in the Markov process from (i,k,m,o, j,l,m,o) to (i-1,k,m,o, j,l,m,o) with intensity of transition $\lambda_{1}$.

- The arrival of a demand for commodity-2 at retailer node makes a state transition in the Markov process from (i,k,m,o, j, l,m,o) to (i,k-1,m,o, j,l,m,o) with intensity of transition $\lambda_{2}$.

- Replenishment of inventory for commodity-1at retailer node makes a state transition in the Markov process from (i,k,m,o, j,l,m,o) to (i,k-1,m,o, $\left.\mathrm{j}+\mathrm{Q}_{1}, 1, \mathrm{~m}-\mathrm{Q}_{1}, \mathrm{o}\right)$ with intensity of transition $\mu_{1}$.

- Replenishment of inventory for commodity-2at retailer node makes a state transition in the Markov process from (i,k,m,o, j,l,m,o) to (i,k-1,m,o, j,l+Q $\left.\mathrm{Q}_{2}, \mathrm{~m}, \mathrm{o}-\mathrm{Q}_{2}\right)$ with intensity of transition $\mu_{2}$.

The infinitesimal generator $\mathrm{R}$ is given by

$$
\mathrm{R}=\left(\begin{array}{cccccc}
\mathrm{A} & \mathrm{B} & 0 & \cdots & 0 & 0 \\
0 & \mathrm{~A} & \mathrm{~B} & \cdots & 0 & 0 \\
0 & 0 & \mathrm{~A} & \cdots & 0 & 0 \\
\vdots & \vdots & \vdots & \vdots & \vdots & \vdots \\
0 & 0 & 0 & \cdots & \mathrm{A} & \mathrm{B} \\
\mathrm{B} & 0 & 0 & \cdots & 0 & \mathrm{~A}
\end{array}\right)
$$

Where $A$ and $B$ are the submatrices of order $\left(\left(S_{2+1}\right) \times\left(\left(S_{2}+1\right) x_{2} Q_{2}\right)\right.$

The entities of $\mathrm{R}$ are given by $\mathrm{R}_{\mathrm{pq}}= \begin{cases}\mathrm{A} & \mathrm{p}=\mathrm{q} ; \mathrm{p}=\mathrm{nQ},(\mathrm{n}-1) \mathrm{Q}, \ldots, \mathrm{Q} \\ \mathrm{B} & \mathrm{p}=\mathrm{q}+\mathrm{Q} ; \mathrm{p}=\mathrm{nQ},(\mathrm{n}-1) \mathrm{Q}, \ldots, \mathrm{Q} \\ \mathrm{B} & \mathrm{p}=\mathrm{Q} ; \mathrm{p}=\mathrm{nQ} \\ \mathrm{O} & \text { otherwise }\end{cases}$

The sub matrices of A are given by $[\mathrm{A}]_{\mathrm{pq}}=\left\{\begin{array}{lll}\mathrm{A}_{1} & \mathrm{p}=\mathrm{q} & ; \mathrm{p}=\mathrm{S}, \mathrm{S}-1, \ldots, \mathrm{s}+1 \\ \mathrm{~B}_{1} & \mathrm{p}=\mathrm{q}+1 & ; \mathrm{p}=\mathrm{S}, \mathrm{S}-1, \ldots, 1 \\ \mathrm{C}_{1} & \mathrm{p}=\mathrm{q} & ; \mathrm{p}=\mathrm{s}, \mathrm{s}-1, \ldots, 1 \\ \mathrm{D}_{1} & \mathrm{p}=\mathrm{q} & ; \mathrm{p}=0 \\ 0 & \text { otherwise }\end{array}\right.$

and 


$$
[B]_{p q}= \begin{cases}M_{1} \quad p=q \quad ; p=S, S-1, \ldots, 1,0 \\ M 2 & p=q+Q ; p=s, s-1, \ldots, 1,0 \\ 0 & \text { otherwise }\end{cases}
$$

The sub matrices of $\mathrm{A}$ and $\mathrm{B}$ are

$$
\begin{aligned}
& {\left[\mathrm{A}_{1}\right]_{\mathrm{pq}}=\left\{\begin{array}{lll}
-\left(\lambda_{1}+\lambda_{2}+\mathrm{i} \gamma_{1}+\mathrm{k} \gamma_{2}\right) & \mathrm{p}=\mathrm{q} & ; \mathrm{p}, \mathrm{i}, \mathrm{k}=\mathrm{S}, \mathrm{S}-1, \ldots, \mathrm{s}+1 \\
\left(\lambda_{2}+\mathrm{k} \gamma_{2}\right) & \mathrm{p}=\mathrm{q}+1 & ; \mathrm{p}, \mathrm{k}=\mathrm{S}, \mathrm{S}-1, \ldots, 1 \\
-\left(\lambda_{1}+\lambda_{2}+\mu_{2}+\mathrm{i} \gamma_{1}+\mathrm{k} \gamma_{2}\right) & \mathrm{p}=\mathrm{q} & ; \mathrm{p}, \mathrm{i}, \mathrm{k}=\mathrm{s}, \mathrm{s}-1, \ldots, 1 \\
-\left(\lambda_{1}+\mu_{2}+\mathrm{i} \gamma_{1}\right) & \mathrm{p}=\mathrm{q} \quad ; \mathrm{p}=\mathrm{0}, \mathrm{i}=\mathrm{S}, \mathrm{S}-1, \ldots, \mathrm{s}+1 \\
0 & \text { Otherwise }
\end{array}\right.} \\
& {\left[B_{1}\right]_{p q}=\left\{\begin{array}{lc}
\left(\lambda_{1}+\mathrm{i} \gamma_{1}\right) & \mathrm{p}=\mathrm{q} \\
0 & \text { Otherwise }
\end{array} ; \mathrm{p}, \mathrm{i}=\mathrm{S}, \mathrm{S}-1, \ldots, 1\right.} \\
& {\left[\mathrm{C}_{1}\right]_{\mathrm{pq}}= \begin{cases}-\left(\lambda_{1}+\lambda_{2}+\mu_{2}+\mathrm{i} \gamma_{1}+\mathrm{k} \gamma_{2}\right) & \mathrm{p}=\mathrm{q} \quad ; \mathrm{p}=\mathrm{s}, \mathrm{s}-1, \ldots, 1 \\
\lambda_{2}+\mathrm{k} \gamma_{2} & \mathrm{p}=\mathrm{q}+1 ; \mathrm{p}=\mathrm{S}, \mathrm{S}-1, \ldots, 1 \\
-\left(\lambda_{1}+\lambda_{2}+\mathrm{i} \gamma+\mathrm{k} \gamma_{2}+\mu_{1}+\mu_{2}\right) & \mathrm{p}=\mathrm{q} \quad ; \mathrm{p}=\mathrm{s}, \mathrm{s}-1, \ldots, 1 \\
-\left(\lambda_{1}+\mathrm{i} \gamma_{1}+\mu_{1}+\mu_{2}\right) & \mathrm{p}=\mathrm{q} \quad ; \mathrm{p}=0 \\
0 & \text { Otherwise }\end{cases} } \\
& {\left[D_{1}\right]_{\mathrm{pq}}= \begin{cases}-\left(\lambda_{2}+\mathrm{k} \gamma_{2}+\mu_{1}\right) & \mathrm{p}=\mathrm{q} \quad ; \mathrm{p}=0 \\
\lambda_{2}+\mathrm{k} \gamma_{2} & \mathrm{p}=\mathrm{q}+1 ; \mathrm{p}=\mathrm{S}, \mathrm{S}-1, \ldots, 1 \\
-\left(\lambda_{2}+\mathrm{k} \gamma_{2}+\mu_{1}+\mu_{2}\right) & \mathrm{p}=\mathrm{q} \quad ; \mathrm{p}=\mathrm{s}, \mathrm{s}-1, \ldots, 1 \\
-\left(\mu_{1}+\mu_{2}\right) & \mathrm{p}=\mathrm{q} \quad ; \mathrm{p}=0 \\
0 & \text { Otherwise }\end{cases} }
\end{aligned}
$$

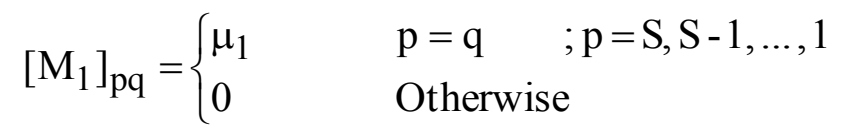

$$
\begin{aligned}
& {\left[\mathrm{M}_{2}\right]_{\mathrm{pq}}=\left\{\begin{array}{ll}
\mu 2 & \mathrm{p}=\mathrm{q}+\mathrm{Q} \\
0 & \text { Otherwise }
\end{array} \quad ; \mathrm{p}=\mathrm{s}, \mathrm{s}-1, \ldots, 1,0\right.}
\end{aligned}
$$

\section{1 Transient Analysis Define the transient probability function}

$$
\mathrm{p}_{\mathrm{i}, \mathrm{k}, \mathrm{m}}(\mathrm{j}, \mathrm{l}, \mathrm{n}: \mathrm{t})=\mathrm{p}_{\mathrm{r}}\left\{\left(\mathrm{I}_{1}(\mathrm{t}), \mathrm{I}_{2}(\mathrm{t}), \mathrm{I}_{\mathrm{D}}(\mathrm{t})\right)=(\mathrm{j}, \mathrm{l}, \mathrm{n}) \mid\left(\mathrm{I}_{1}(0), \mathrm{I}_{2}(0), \mathrm{I}_{\mathrm{D}}(0)\right)=(\mathrm{i}, \mathrm{k}, \mathrm{m})\right\} \text {. }
$$

The transient matrix for $t \geq 0$ is of the form $P(t)=\left(p_{i, k}, m(j, 1, n: t)\right)_{(i, k, m)(j, 1, n) \in E}$ satisfies the Kolmogorovforward equation

$$
\mathrm{P}^{\prime}(\mathrm{t})=\mathrm{P}(\mathrm{t}) \cdot \mathrm{R}
$$

where $R$ is the infinitesimal generator of the process $\{I(t), t \geq 0\}$.

The solutions of (1) can be written in the form $P(t)=P(0) e^{R t}=e^{R t}$

Where the matrix $\mathrm{e}^{\mathrm{Rt}}=\mathrm{I}+\sum_{\mathrm{n}=1}^{\infty} \frac{\mathrm{R}^{\mathrm{n}} \mathrm{t}^{\mathrm{n}}}{\mathrm{n}}$.

Assume that Eigenvalues of $\mathrm{R}$ are all distinct. Then from the spectral theorem of matrices, we have $\mathrm{R}=\mathrm{HDH}^{-1}$ Where $\mathrm{H}$ is a non-singular matrix(formed with the right eigenvectors of $\mathrm{R}$ ) and $\mathrm{D}$ is the diagonal matrix having for its diagonal elements the Eigenvalues of $R$. now , 0 is an Eigen value of $R$ and $d_{i} \neq 0, i=1,2, \ldots \ldots \ldots m$ are the other distinct Eigenvalues, then $\mathrm{D}=\left(\begin{array}{ccccc}0 & 0 & \ldots & \ldots & 0 \\ 0 & \mathrm{~d}_{1} & \ldots & \ldots & 0 \\ \ldots & \ldots & \ldots & \ldots & \ldots \\ \ldots & \ldots & \ldots & \ldots & \ldots \\ 0 & 0 & \ldots & \ldots & \mathrm{d}_{\mathrm{m}}\end{array}\right)$ 
We then have $\mathrm{D}^{\mathrm{n}}=\left(\begin{array}{ccccc}0 & 0 & \ldots & \ldots & 0 \\ 0 & \mathrm{~d}_{1}^{\mathrm{n}} & \ldots & \ldots & 0 \\ \ldots & \ldots & \ldots & \ldots & \ldots \\ \ldots & \ldots & \ldots & \ldots & \ldots \\ 0 & 0 & \ldots & \ldots & \mathrm{d}_{\mathrm{m}}^{\mathrm{n}}\end{array}\right) \quad$ and $\quad \mathrm{R}^{\mathrm{n}}=\mathrm{H} \mathrm{D}^{\mathrm{n}} \mathrm{H}^{-1}$

We have $\mathrm{P}(\mathrm{t})=\mathrm{I}+\sum_{n=1}^{\infty} \frac{\left(H D^{n} H^{-1}\right)}{n !}=\mathrm{H}\left\{I+\sum_{n=1}^{\infty} \frac{D^{n} t^{n}}{n !}\right\} \mathrm{H}^{-1}=\mathrm{He}^{\mathrm{Dt}} \mathrm{H}^{-1}$, where

$\mathrm{e}^{\mathrm{Dt}}=\left(\begin{array}{ccccc}1 & 0 & \cdots & \cdots & 0 \\ 0 & \mathrm{e}^{\mathrm{d} \mathrm{t}^{\mathrm{t}}} & \cdots & \cdots & 0 \\ \cdots & \cdots & \cdots & \cdots & \cdots \\ \cdots & \cdots & \cdots & \cdots & \cdots \\ 0 & 0 & \cdots & \cdots & \mathrm{e}^{\mathrm{d}_{\mathrm{m}}} \mathrm{t}\end{array}\right)$

The right-hand side of above equation gives explicit solution of the matrix $\mathrm{p}(\mathrm{t})$. Note that even in the general case when the Eigenvalues of $\mathrm{R}$ are not necessarily distinct, a canonical representation of $\mathrm{R}=\mathrm{SZS}^{-1}$ exists.

3.2 Steady state analysis

Since the state space is finite and $\mathrm{R}$ is irreducible, the stationary probability vector $\Pi$ for the generator $\mathrm{R}$ always exists and satisfies $\Pi \mathrm{R}=0 \quad \Pi \mathrm{e}=1$

The vector $\Pi$ can be represented by

$$
\Pi=\left(\Pi^{<\mathrm{Q} 1, \mathrm{Q} 2>}, \Pi^{<2 \mathrm{Q} 1,2 \mathrm{Q} 2>}, \Pi^{<3 \mathrm{Q} 1,3 \mathrm{Q} 2>}, \ldots . ., \Pi^{<\mathrm{n} 1 \mathrm{Q} 1, \mathrm{n} 2 \mathrm{Q} 2>}\right.
$$

Now the structure of R shows, the model under study is a finite birth death model in the Markovian environment. Hence we use the Gaver algorithm for computing the limiting probability vector. For the sake of completeness we provide the algorithm here.

Algorithm:

1. Determine recursively the matrix $\mathrm{D}_{\mathrm{n}}, 0 \leq \mathrm{n} \leq \mathrm{N}$ by using

$$
\begin{aligned}
\mathrm{D}_{0} & =A_{0} \\
\mathrm{D}_{\mathrm{n}} & =A_{n}+B_{n}\left(-D_{n-1}^{-1}\right) C, \quad n=1,2, \ldots . K
\end{aligned}
$$

2. Solve the system

$$
\Pi^{<N>} D_{N}=0 \text {. }
$$

3. Compute recursively the vector $\Pi^{<n>}, \quad n=N-1, \ldots . ., 0$ using

$$
\Pi^{<n>}=\Pi^{<n+1>} B_{n+1}\left(-D_{n}^{-1}\right), n=n-1, \ldots \ldots, 0 .
$$

4. Re-normalize the vector $\Pi$, using

$$
\Pi e=1 \text {. }
$$

\section{Performance measures}

Consider the event $r_{R}$ and $r_{D}$ of reorders at node Retailer and Distributor respectively. Observe that $r_{D}$ event occur whenever the inventory level at $D_{i}$ node reaches 0 whereas the $r_{R}$ event occurs whenever the inventory level at retailer nodes reaches reorder level $\mathrm{s}_{1}$ or $\mathrm{s}_{2}$.

\subsection{Mean reorder rate}

Let $I_{R 1}$ and $I_{R 2}$ denote the expected inventory level in the steady state at retailer node for the commodity 1 and 2 , and $I_{D 1}, I_{D 2}$ denote the expected inventory level at distribution centre for the commodity 1 and 2 respectively. They are defined as

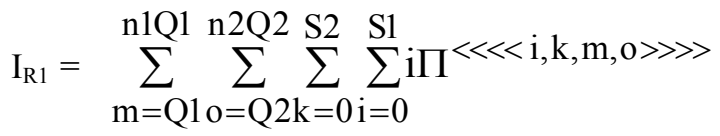

$$
\begin{aligned}
& \mathrm{I}_{\mathrm{R} 2}=\sum_{\mathrm{m}=\mathrm{Q} 1 \mathrm{o}=\mathrm{Q} 2 \mathrm{k}=0}^{\mathrm{n} 1 \mathrm{Q} 1} \sum_{\mathrm{i}=0}^{\mathrm{n} 2 \mathrm{Q} 2} \sum^{\mathrm{S} 2} \mathrm{k}^{\mathrm{S} 1} \Pi^{<<<i, \mathrm{k}, \mathrm{m}, \mathrm{o} \gg \gg \gg>}
\end{aligned}
$$




$$
\begin{aligned}
& \mathrm{I}_{\mathrm{D} 1}=\sum_{\mathrm{m}=\mathrm{Q} 1 \mathrm{o}=\mathrm{Q} 2 \mathrm{k}=0 \mathrm{n}=0}^{\mathrm{n} 1 \mathrm{n} 2 \mathrm{Q} 2} \sum_{\mathrm{i}=0}^{\mathrm{S} 2} \sum^{\mathrm{S} 1} \mathrm{~m} \Pi^{<<<<\mathrm{i}, \mathrm{k}, \mathrm{m}, \mathrm{o} \gg \gg>>} \\
& \mathrm{I}_{\mathrm{D} 2}=\sum_{\mathrm{m}=\mathrm{Q} 1 \mathrm{o}=\mathrm{Q} 2 \mathrm{k}=0}^{\mathrm{n} 2 \mathrm{Q} 2} \sum_{\mathrm{i}=0}^{\mathrm{S} 2} \sum^{\mathrm{S} 1} \mathrm{o} \Pi^{<<<<\mathrm{i}, \mathrm{k}, \mathrm{m}, \mathrm{o} \gg \gg>>}
\end{aligned}
$$

4.2 Mean reorder rate.

The mean reorder rate at retailer node and Distributor for the Commodity 1 and 2 are given by is given

$$
\begin{aligned}
& \mathrm{r}_{\mathrm{R} 1}=\sum_{\mathrm{m}=\mathrm{Q} 1 \mathrm{o}=\mathrm{Q} 2}^{\mathrm{n} 1 \mathrm{Q} 1} \sum_{\mathrm{k}=0}^{\mathrm{n} 2 \mathrm{Q} 2}\left(\lambda_{1}+(\mathrm{s} 1+1) \gamma_{1}\right) \Pi^{<\ll<\mathrm{s} 1+1, \mathrm{k}, \mathrm{m}, \mathrm{o} \gg \gg \gg>} \\
& \left.\mathrm{r}_{\mathrm{R} 2}=\sum_{\mathrm{m}=\mathrm{Q} 1 \mathrm{o}=\mathrm{Q} 2 \mathrm{i}=0}^{\mathrm{n} 1 \mathrm{Q} 1} \sum^{\mathrm{n} 2 \mathrm{Q} 2} \mathrm{~S} 1 \lambda_{2}+(\mathrm{s} 2+1) \gamma_{2}\right) \Pi^{<<\mathrm{i}, \mathrm{s} 2+1, \mathrm{~m}, \mathrm{o} \gg \gg} \\
& \mathrm{r}_{\mathrm{D} 1}=\sum_{0=\mathrm{Q} 2}^{\mathrm{n} 2 \mathrm{Q} 2} \sum_{\mathrm{k}=\mathrm{s} 2+1}^{\mathrm{S} 2} \sum_{\mathrm{i}=0}^{\mathrm{S} 1}(\mu 1) \Pi^{<<<\mathrm{i}, \mathrm{k}, \mathrm{Q} 1, \mathrm{o} \gg \gg \gg>} \\
& \mathrm{r}_{\mathrm{D} 1}=\sum_{\mathrm{m}=\mathrm{Q} 1}^{\mathrm{n} 1 \mathrm{Q} 1} \sum_{\mathrm{k}=\mathrm{s} 2+1 \mathrm{i}=0}^{\mathrm{S} 2} \sum_{\mathrm{S} 1}^{\mathrm{S}}(\mu 2) \Pi^{\ll<<\mathrm{i}, \mathrm{k}, \mathrm{m}, \mathrm{Q} 2 \gg \gg \gg}
\end{aligned}
$$

4.4 Shortage rate

Shortage occurs only at retailer node and the shortage rate for the commodity 1 and 2 at retailer is denoted by $\alpha_{R 1}$ and $\alpha_{R 2}$ which is given by

\section{Cost Analysis}

$$
\begin{aligned}
& \alpha_{\mathrm{R} 1}=\sum_{\mathrm{m}=\mathrm{Q} 1}^{\mathrm{n} 1 \mathrm{Q} 1} \sum_{\mathrm{k}=\mathrm{s} 2+1}^{\mathrm{S} 2} \sum_{\mathrm{k}=0}^{\mathrm{S} 2}(\mu 2) \Pi^{<<<<0, \mathrm{k}, \mathrm{m}, \mathrm{o} \gg \gg \gg>} \\
& \alpha_{\mathrm{R} 2}=\sum_{\mathrm{m}=\mathrm{Q} 1 \mathrm{Q} 1}^{\mathrm{n} 2} \sum_{\mathrm{k}=\mathrm{s} 2+1}^{\mathrm{S}} \sum_{\mathrm{i}=0}^{\mathrm{S} 1}(\mu 2) \Pi^{<<<\mathrm{i}, 0, \mathrm{~m}, \mathrm{o} \gg \gg \gg}
\end{aligned}
$$

In this section we analyze the cost structure for the proposed models by considering the minimization of the steady state total expected cost per time.

The long run expected cost rate for the model is defined to be

$$
\mathrm{TC}\left(\mathrm{s}_{1}, \mathrm{~s}_{2}, \mathrm{Q}_{1}, \mathrm{Q}_{2}\right)=\mathrm{h}_{\mathrm{R} 1} \mathrm{I}_{\mathrm{R} 1}+\mathrm{h}_{\mathrm{R} 2} \mathrm{I}_{\mathrm{R} 2}+\mathrm{h}_{\mathrm{D} 1} \mathrm{I}_{\mathrm{D} 1}+\mathrm{h}_{\mathrm{D} 2} \mathrm{I}_{\mathrm{D} 2}+\mathrm{k}_{1} \mathrm{r}_{\mathrm{R} 1}+\mathrm{k} 2 \mathrm{r}_{\mathrm{R} 2}+\mathrm{g}_{\mathrm{R} 1} \alpha_{\mathrm{R} 1}+\mathrm{g} 2 \alpha 2
$$

Although, we have not proved analytically the convexity of the cost function $\mathrm{C}(\mathrm{s}, \mathrm{Q})$, our experience with considerable number of numerical examples indicates that $C(s, Q)$ for fixed $Q$ to be convex in s. In some cases, it turned out to be an increasing function of $\mathrm{s}$. Hence, we adopted the numerical search procedure to determine the optimal values $s^{*}$, consequently, we obtain optimal $n^{*}$. For large number of parameters, our calculation of $\mathrm{C}(\mathrm{s}, \mathrm{Q})$ revealed a convex structure for the same. Hence, we adopted a numerical search procedure to obtain the optimal value $\mathrm{s}_{\mathrm{i}}^{*}$ for each $\mathrm{S}_{\mathrm{i}}(\mathrm{i}=1,2)$.

\section{Numerical Example}

Example: We analyzed the following in the numerical section.

1. Table 1 and Table 2 give the effect of total cost function by varying the set-up cost, holding cost, shortage cost and the back ordering cost.

2. Figure 1 shows that the effect of the demand rate $\lambda$ and lead time $\mu$ on long run expected cost.

\begin{tabular}{|l|l|l|l|l|l|}
\hline & $\mathrm{h}_{\mathrm{D}}=0.04$ & $\mathrm{~h}_{\mathrm{D}}=0.08$ & $\mathrm{~h}_{\mathrm{D}}=0.12$ & $\mathrm{~h}_{\mathrm{D}}=0.16$ & 220.960793 \\
\hline $\mathrm{h}_{\mathrm{R}}=0.002000$ & 220.112907 & 220.395536 & 220.678164 & 221.243421 & 221.247694 \\
\hline $\mathrm{h}_{\mathrm{R}}=0.004000$ & 220.117181 & 220.399809 & 220.682438 & 220.965066 & 220.969339 \\
\hline $\mathrm{h}_{\mathrm{R}}=0.006000$ & 220.121454 & 220.404082 & 220.686711 & 220.251968 & 221.256241 \\
\hline $\mathrm{h}_{\mathrm{R}}=0.008000$ & 220.125727 & 220.408356 & 220.690984 & 220.973613 & 221.260514 \\
\hline $\mathrm{h}_{\mathrm{R}}=0.010000$ & 220.130001 & 220.412629 & 220.695258 & 220.977886 \\
\hline
\end{tabular}


Table 1: $h_{R}$ vs $h_{D}$ on TC $(12,18,4,6)$

\begin{tabular}{|l|l|l|l|l|l|}
\hline & $\mathrm{g}_{\mathrm{R}}=0.2$ & $\mathrm{~g}_{\mathrm{R}}=0.4$ & $\mathrm{~g}_{\mathrm{R}}=0.6$ & $\mathrm{~g}_{\mathrm{R}}=0.8$ & $\mathrm{~g}_{\mathrm{R}}=0.10$ \\
\hline $\mathrm{k}_{\mathrm{D}}=10$ & 193.290714 & 199.355262 & 205.419811 & 211.484359 & 217.548907 \\
\hline $\mathrm{k}_{\mathrm{D}}=15$ & 204.361368 & 210.425917 & 216.490465 & 222.555013 & 228.619561 \\
\hline $\mathrm{k}_{\mathrm{D}}=20$ & 215.432023 & 221.496571 & 227.561119 & 233.625667 & 239.690215 \\
\hline $\mathrm{k}_{\mathrm{D}}=25$ & 226.502677 & 232.567225 & 238.631773 & $244 . .696321$ & 250.760869 \\
\hline $\mathrm{k}_{\mathrm{D}}=30$ & 237.573331 & 243.637879 & 249.702427 & 255.766975 & 261.831523 \\
\hline
\end{tabular}

Table $2: \mathrm{k}_{\mathrm{R}}$ vs $\mathrm{g}_{\mathrm{R}}$ on $\mathrm{TC}(12,18,4,6)$

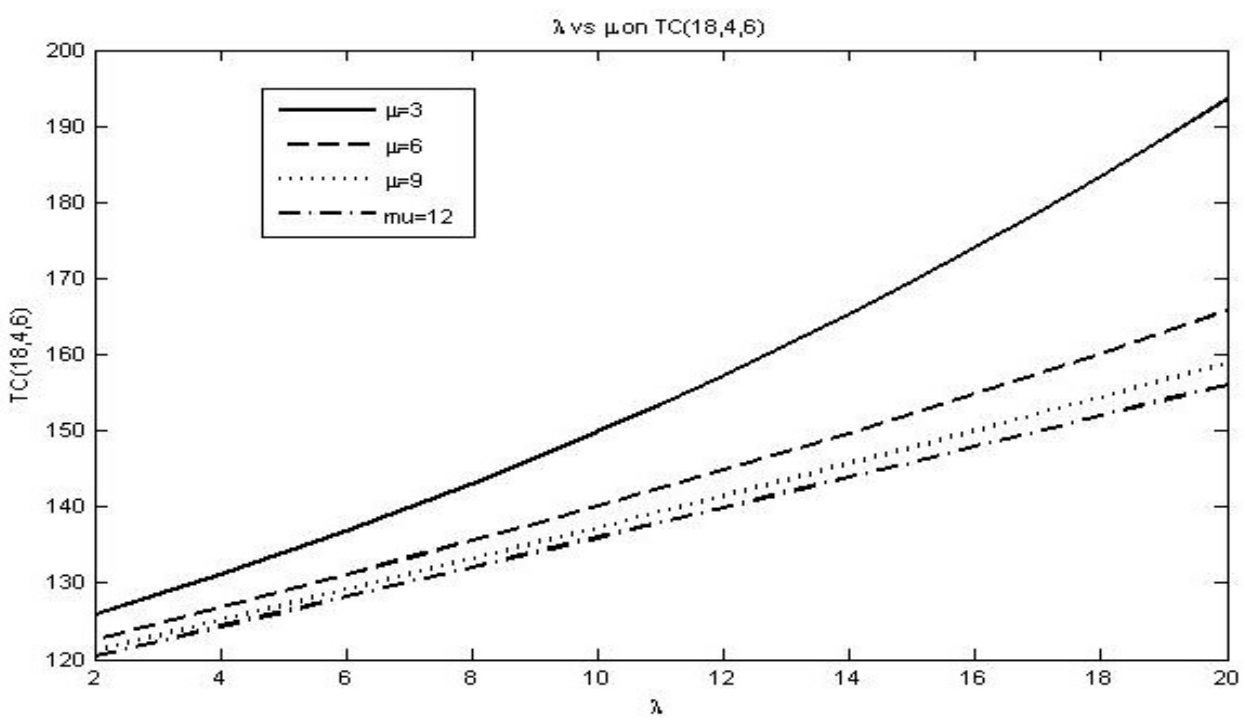

From the numerical work, we conclude the following:

1. As is to be expected $\lambda_{1}$ and $\lambda_{2}$, increases total cost increases, $\mu_{1}$ and $\mu_{2}$ increases total cost decreases.

\section{Concluding remarks}

2. Also the total cost increases when the costs $h_{D}, h_{R}, g_{R}$ and $k_{R}$ increases.

In this article, we analyzed a continuous review stochastic perishable inventory system. The arrival of demands form a Poisson distribution. The life time of each items, lead times of reorder forms independent exponential distributions. The model is analyzed within the framework of Markov processes. Joint probability distribution of inventory level at retailer and is obtained in the steady state. Various system performance measures are derived and the long-run expected cost rate is calculated. By assuming a suitable cost structure on the inventory system, we have presented extensive numerical illustrations to show the effect of change of values for constants on the total expected cost rate. It would be interesting to analyze the problem discussed in this article where the life time of items are constant. Naturally, with the inclusion of constant life time of each items, the problem will be more challenging. Another important extension could be made by relaxing the assumption of exponentially distributed lead times to a class of arbitrarily distributed lead times using techniques from renewal theory and semi-regenerative processes. Once this is done, the general model can be used to generate various special cases. For example, three different lead time distributions one with coefficient of variation greater than one, one with coefficient of variation less than one and another with coefficient of variation equal to one (this model) can be compared. Cost analysis can then be carried out for (s, Q), (s, S) and lot-for-lot models using each of the three different lead time distributions to determine which policy is optimal for any given lead time distribution. The author is currently working on the above extensions, and these will be reported in future publications.

\section{References}

[1] Anbazhagan N \& Arivarignan G, 2000, Two-commodity continuous review inventory system with coordinated reorder policy, International Journal of Information and Management Sciences, 11(3), pp. 19-30.

[2] Arivarignan G \& Sivakumar B, 2003, Inventory system with renewal demands at service facilities, pp. 108-123 in Srinivasan SK \& Vijayakumar A (Eds), Stochastic point processes, Narosa Publishing House, New Delhi.

[3] Axsäter, S. 1990. Simple solution procedures for a class of two-echelon inventory problems. Operations research, 38(1), 64-69.

[4] Benita M. Beamon. 1998. Supply Chain Design and Analysis: Models and Methods. International Journal of Production Economics.Vol.55, No.3, pp.281 294.

[5] Cinlar, E. Introduction to Stochastic Processes. Prentice Hall, Englewood Cliffs, NJ, 1975.

[6] Clark, A. J. and H. Scarf, 1960. Optimal Policies for a Multi-Echelon Inventory Problem.Management Science, 6(4): 475-490.

[7] Elango C, 2001, A continuous review perishable inventory system at service facilities, PhD dissertation, Madurai Kamaraj University, Madurai.

[8] Goyal SK \& Satir T, 1989, Joint replenishment inventory control: Deterministic and stochastic models, European Journal of Operational Research, 38, pp. 2-13.

[9] Harris, F., 1915, Operations and costs, Factory management series, A.W. Shah Co., Chicago,48 - 52. 
[10] He QM, Jewkes EM \& Buzacott J, 1998, An efficient algorithm for computing the optimal replenishment policy for an inventoryproduction system, pp. 381-402, in Alfa A \& Chakravarthy S (Eds), Advances in matrix analytic methods for stochastic models, Notable Publications, Inc., Englewood Cliffs (NJ).

[11] Kalpakam S \& Arivarignan G, 1993, A coordinated multicommodity (s, S) inventory system, Mathematical Computer Modelling, 18, pp. 69-73.

[12] Krishnan.K, 2007, Stochastic Modeling In Supply Chain Management System, unpublished Ph. D., Thesis, Madurai Kamaraj University, Madurai

[13] Krishnamoorthy, A., Iqbal Basha, R. and Lakshmy, B. (1994), Analysis of a two commodity problem , International Journal of Information and Management Sciences, 5,1, 127 - 136

[14] Nahmias S, 1982, Perishable inventory theory: A review, Operations Research, 30, pp. 680-708.

[15] Sherbrooke, C., 1968. METRIC: A multi-echelon technique for recoverable item control. Operations Research. $16(1), 122$ - 141.

[16] Yadavalli VSS, Van Schoor CdeW, Strasheim JJ \& Udayabaskaran S, 2004, A single product perishing inventory model with demand interaction, ORiON, 20(2), pp. 109-124. 